\title{
Rapid determination of germanium and tin by ion chromatography
}

\author{
Qun Sun, Huitong Wang, Shifen Mou* \\ Research Centre for Eco-Environmental Sciences, Academia Sinica, P.O. Box 2871, Beijing 100085, China
}

First received 17 June 1993; revised manuscript received 14 March 1995; accepted 17 March 1995

\begin{abstract}
A method was established for the simultaneous determination of germanium and tin in one run by ion chromatography. Using a selected eluent, Ge and Sn were separated on a bifunctional ion-exchange column, followed by a postcolumn chromogenic reaction and spectrophotometric detection at $520 \mathrm{~nm}$. The whole procedure was completed within $5 \mathrm{~min}$ with high sensitivity and selectivity at the low- $\mu \mathrm{g} / \mathrm{l}$ level. The results of real sample analysis were satisfactory.
\end{abstract}

\section{Introduction}

In research in the metallurgical industry and on the analysis of mineral resources, the determination of $\mathrm{Ge}$ and $\mathrm{Sn}$ is necessary. During the past 30 years, with the discovery of large amounts of germanium in many kinds of rare medicinal herbs, the function of germanium in pharmacology and biology has attracted increasing interest. It has been found that germanium is a very important element in the human body which can improve the physical condition [1]. Current methods for the determination of $\mathrm{Ge}$ and $\mathrm{Sn}$ include spectrophotometric measurement [2-8], atomic absorption spectrometry (AAS) [9-11] and polarography $[12,13]$. Among these methods, spectrophotometry has frequently been used but it is less sensitive and selective and always needs different sample preparation. AAS with hydride generation is a relatively powerful

* Corresponding author. way to determine $\mathrm{Ge}$ and $\mathrm{Sn}$, with detection limits of $0.6 \mathrm{ng} / \mathrm{l}$ for $\mathrm{Ge}$ and $1.7 \mathrm{ng} / \mathrm{l}$ for $\mathrm{Sn}$ $[1,9,14]$. However, ion chromatography has not been reported for the simultaneous determination of Ge and Sn. In this paper, we present a rapid method of ion chromatographic separation followed by spectrophotometric detection which shows high sensitivity and a lack of interferences.

\section{Experimental}

\subsection{Materials}

A stock standard solution of germanium (1000 $\mathrm{mg} / \mathrm{l}$ ) was obtained by dissolving germanium powder in $30 \%$ hydrogen peroxide solution with solid sodium hydroxide [8]. The $\mathrm{pH}$ of the $\mathrm{Ge}$ solution was adjusted to $<2$ with sulfuric acid.

A stock standard solution of Sn $(1000 \mathrm{mg} / \mathrm{l})$ was prepared by dissolving tin metal in hot, concentrated hydrochloric acid and adding hy- 
droxylamine hydrochloride to reduce $\operatorname{Sn}($ IV) to Sn(II).

The eluent was a mixture of $0.15 \mathrm{~mol} / 1$ sulfuric acid and $0.05 \mathrm{~mol} / 1$ sodium sulfate.

A phenylfluorone stock standard solution (1.5 $\mathrm{mmol} / \mathrm{l}$ ) was prepared by dissolving $0.48 \mathrm{~g}$ of phenylfluorone in $500 \mathrm{ml}$ of ethanol, adding 50 $\mathrm{ml}$ of $6.0 \mathrm{~mol} / \mathrm{l}$ sulfuric acid and filtering through a $0.45-\mu \mathrm{m}$ filter-paper. The filtrate was diluted to $1000 \mathrm{ml}$ with deionized water.

A $2 \%$ solution of the cationic surfaceactive agent cetyltrimethylammonium bromide (CTAB) was prepared by dissolving $10 \mathrm{~g}$ of $\mathrm{CTAB}$ in $400 \mathrm{ml}$ of hot water and diluting to 500 $\mathrm{ml}$ with deionized water.

A $0.20 \mathrm{~mol} / 1$ oxalic acid solution was prepared by dissolving $16.2 \mathrm{~g}$ of oxalic acid in $500 \mathrm{ml}$ of deionized water.

The postcolumn reagent was prepared by mixing $250 \mathrm{ml}$ of $1.5 \mathrm{mmol} / \mathrm{l}$ phenylfluorone with $120 \mathrm{ml}$ of $2 \%$ CTAB and $50 \mathrm{ml}$ of $0.2 \mathrm{~mol} / 1$ oxalic acid, adding $40 \mathrm{ml}$ of concentrated sulfuric acid and diluting to $500 \mathrm{ml}$ with deionized water.

All chemicals were of analytical-reagent grade from China.

\subsection{Chromatographic apparatus}

All chromatography was performed on a Dionex 2010 IC system equipped with a basic ion chromatographic module, a spectrophotometric detector, a postcolumn reactor and a $50-\mu 1$ sample loop. The separation column was a Dionex IonPac CS5 with an IonPac CG5 guard column. The chromatogram was plotted by a Dionex recorder.

\subsection{Procedure}

Fig. 1 shows the chromatographic configuration for the determination of $\mathrm{Ge}$ and $\mathrm{Sn}$. The pump delivered the $\mathrm{H}_{2} \mathrm{SO}_{4}-\mathrm{Na}_{2} \mathrm{SO}_{4}$ eluent at the rate of $1.0 \mathrm{ml} / \mathrm{min}$. The postcolumn reactor provided a flow-rate of $0.5 \mathrm{ml} / \mathrm{min}$ for the above postcolumn reagent. The wavelength for determination of $\mathrm{Ge}$ and $\mathrm{Sn}$ was set at $520 \mathrm{~nm}$. In order to make the postcolumn chromogenic reaction complete, the eluent and postcolumn

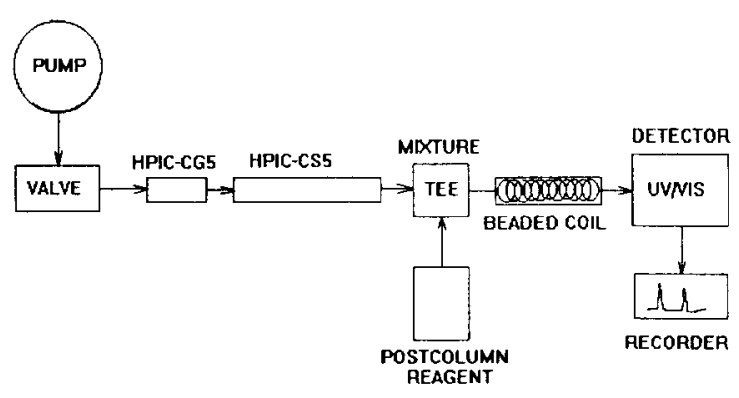

Fig. 1. Chromatographic configuration.

reagent must be mixed in a beaded mixing coil $80 \mathrm{~cm}$ long. Fig. 2 shows the chromatogram of germanium and tin.

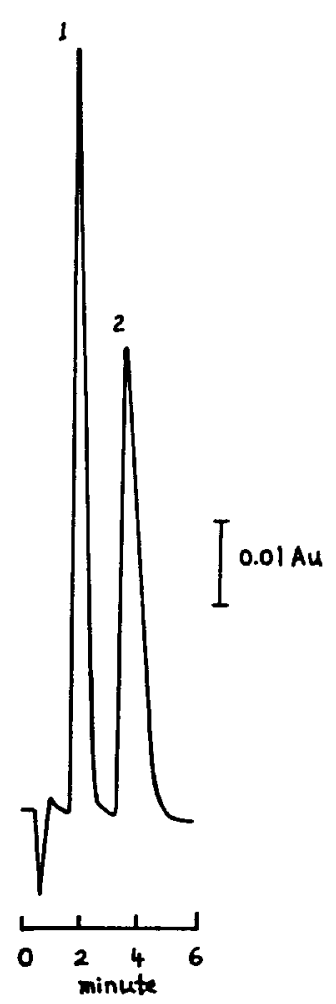

Fig. 2. Chromatogram of germanium and tin. Peaks: $1=$ $\mathrm{HGeO}_{3}^{-}(0.5 \mathrm{mg} / \mathrm{l}) ; 2=\mathrm{Sn}^{2+}(1.0 \mathrm{mg} / \mathrm{l})$. Separation column, Dionex IonPac CS5; guard column, IonPac CG5; sample loop, $50 \mu \mathrm{l}$; detection wavelength, $520 \mathrm{~nm}$; eluant, 0.15 $\mathrm{mol} / 1 \mathrm{H}_{2} \mathrm{SO}_{4}-0.05 \mathrm{~mol} / 1 \mathrm{Na}_{2} \mathrm{SO}_{4}$; flow-rate, $1.0 \mathrm{ml} / \mathrm{min}$; postcolumn reagent, $0.75 \mathrm{mmol} / 1$ phenylfluorone- $0.5 \%$ CTAB-1.5 mol/1 $\mathrm{H}_{2} \mathrm{SO}_{4}-0.02 \mathrm{~mol} / 1$ oxalic acid; flow-rate, $0.5 \mathrm{ml} / \mathrm{min}$. 


\section{Results and discussion}

\subsection{Choice of separation column}

The stable oxidation state of germanium in solution is Ge(IV) [1]. In aqueous acidic solution, $\mathrm{Ge}$ exists primarily in its oxy acid anion form, $\mathrm{HGeO}_{3}^{-}$. The stable valency of tin in solution is $\mathrm{Sn}(\mathrm{II})$ [14]. In order to separate $\mathrm{HGeO}_{3}^{-}$and $\mathrm{Sn}^{2+}$ simultaneously, we chose a Dionex IonPac CS5 column as the separation column, as its resin contains both anion- and cation-exchange groups.

\subsection{Selection of eluent}

In acidic solution, $\mathrm{HGeO}_{3}^{-}$is stable but $\mathrm{Sn}^{2+}$ can be hydrolyzed to $\mathrm{SnOH}^{+}$at $\mathrm{pH}>1.5$. The eluent used for separating $\mathrm{HGeO}_{3}^{-}$and $\mathrm{Sn}^{2+}$ should be maintained at $\mathrm{pH}<1.5$ to keep them in their stable state. In order to separate $\mathrm{HGeO}_{3}^{-}$ anions and $\mathrm{Sn}^{2+}$ cations simultaneously in one run, the eluent should contain both anions and cations since the separation mechanism of the IonPac CS5 column is ion exchange.

Initially, $\mathrm{HCl}$ was used as the eluent, but more than two peaks were observed and the reproducibility of the response was very poor. The reason could be the complex reaction between germanium and $\mathrm{HCl}$. Germanium can form $\mathrm{GeCl}_{4}, \mathrm{GeCl}_{5}^{-}, \mathrm{GeCl}_{6}^{2-}$ and $\mathrm{H}_{2} \mathrm{GeO}_{3}$ in $\mathrm{HCl}$ [1]. Owing to the presence of $\mathrm{H}_{2} \mathrm{SO}_{4}$ in the postcolumn chromogenic reagent, $\mathrm{H}_{2} \mathrm{SO}_{4}$ was selected for a trial. However, the results showed that the retention time of $\mathrm{Sn}^{2+}$ was too long with elution using $\mathrm{H}_{2} \mathrm{SO}_{4}$, as $\mathrm{H}^{+}$is a relatively weak eluting ion which has a weak affinity to the cation-exchange resin of the IonPac CS5 column. To decrease the retention time of $\mathrm{Sn}^{2+}$ and maintain the retention time of $\mathrm{HGeO}_{3}^{-}$, we added $\mathrm{Na}_{2} \mathrm{SO}_{4}$ to the $\mathrm{H}_{2} \mathrm{SO}_{4}$ eluent, as $\mathrm{Na}^{+}$is a stronger eluting ion than $\mathrm{H}^{+}$. When sodium sulfate was added to the eluent, the concentration of sulfuric acid must be lowered, as the sodium sulfate contributes not only $\mathrm{Na}^{+}$cations but also $\mathrm{SO}_{4}^{2-}$ anions to the eluent. While keeping the concentration of $\mathrm{SO}_{4}^{2-}$ constant, we
Table 1

Effect of concentrations of $\mathrm{H}_{2} \mathrm{SO}_{4}$ and $\mathrm{Na}_{2} \mathrm{SO}_{4}$ on the retention times of $\mathrm{HGeO}_{3}^{-}$and $\mathrm{Sn}^{2+}$

\begin{tabular}{llll}
\hline $\begin{array}{llll}\mathrm{Na}_{2} \mathrm{SO}_{4} \\
(\mathrm{~mol} / \mathrm{l})\end{array}$ & $\begin{array}{l}\mathrm{H}_{2} \mathrm{SO}_{4} \\
(\mathrm{~mol} / 1)\end{array}$ & \multicolumn{2}{l}{ Retention time (min) } \\
\cline { 3 - 4 } & & $\mathrm{HGeO}_{3}^{-}$ & $\mathrm{Sn}^{2+}$ \\
\hline 0 & 0.20 & 2.0 & 6.2 \\
0.05 & 0.15 & 2.0 & 4.0 \\
0.10 & 0.10 & 2.0 & 3.2 \\
0.20 & 0 & 2.1 & 2.0 \\
\hline
\end{tabular}

changed the $\mathrm{H}_{2} \mathrm{SO}_{4} / \mathrm{Na}_{2} \mathrm{SO}_{4}$ concentration ratio in the eluent. Table 1 gives the results of the effect of the concentration of $\mathrm{H}_{2} \mathrm{SO}_{4}$ and $\mathrm{Na}_{2} \mathrm{SO}_{4}$ on the resolution of $\mathrm{Ge}$ and $\mathrm{Sn}$. With increase in the concentration of $\mathrm{Na}^{+}$, the retention time of $\mathrm{Sn}^{2+}$ decreased, whereas the retention time of $\mathrm{HGeO}_{3}^{-}$remained the same. We adopted $0.15 \mathrm{~mol} / \mathrm{l} \quad \mathrm{H}_{2} \mathrm{SO}_{4}-0.05 \mathrm{~mol} / \mathrm{l}$ $\mathrm{Na}_{2} \mathrm{SO}_{4}$ as the eluent.

\subsection{Selection of chromogenic reagent}

Since the late 1960s, phenylfluorone and $\mathrm{CTAB}$ have been used as effective chromogenic reagents in spectrophotometry for the determination of $\mathrm{Ge}(\mathrm{IV})$ and $\mathrm{Sn}$ (II) [7]. However, the postcolumn reaction in ion chromatography is different from that in spectrophotometry; it occurs under fluxional conditions within a short reaction time. Hence the chromogenic conditions of spectrophotometry cannot be used directly, and should be modified. In order to make the postcolumn reaction complete and rapid, the conditions for ion chromatography were studied as discussed below.

\section{Concentration of phenylfluorone}

Phenylfiuorone (9-phenyl-2,3,7-trihydroxy-6fluorone) is a highly sensitive chromogenic reagent for $\mathrm{Ge}(\mathrm{IV})$ and $\mathrm{Sn}$ (II). The peak heights of $\mathrm{Ge}$ and $\mathrm{Sn}$ were in direct proportion to the concentration of phenylfluorone. However, when the concentration of phenylfluorone was $>0.5 \mathrm{mmol} / \mathrm{l}$, the peak heights of $\mathrm{Ge}$ and $\mathrm{Sn}$ became constant. Therefore, $0.75 \mathrm{mmol} / \mathrm{l}$ 
phenylfluorone in the postcolumn reagent was selected for the determination of $\mathrm{Ge}$ and $\mathrm{Sn}$.

\section{Effect of concentration of $\mathrm{H}_{2} \mathrm{SO}_{4}$}

The function of $\mathrm{H}_{2} \mathrm{SO}_{4}$ in the postcolumn reaction is to adjust the acidity of the reagent, which directly affects the absorbance of the complexes of $\mathrm{HGeO}_{3}^{-}$and $\mathrm{Sn}^{2+}$. The experiment showed that, with increase in the concentration of $\mathrm{H}_{2} \mathrm{SO}_{4}$, the response of $\mathrm{HGeO}_{3}^{-}$and $\mathrm{Sn}^{2+}$ was improved until the concentration of $\mathrm{H}_{2} \mathrm{SO}_{4}$ reached $1.0 \mathrm{~mol} / \mathrm{l}$. At concentrations of $\mathrm{H}_{2} \mathrm{SO}_{4}$ between 1.0 and $2.0 \mathrm{~mol} / \mathrm{l}$, the absorbances of $\mathrm{HGeO}_{3}^{-}$and $\mathrm{Sn}^{2+}$ were constant. Hence 1.5 mol/ $/ \mathrm{H}_{2} \mathrm{SO}_{4}$ was used in the postcolumn reaction.

\section{Concentration of CTAB}

The cationic surface-active agent CTAB plays a very important role in the postcolumn reaction. It forms tri-complex compounds with $\mathrm{HGeO}_{3}^{-}$or $\mathrm{Sn}^{2-}$ and phenylfluorone, which increase the absorbance of the products in the postcolumn chromogenic reaction $[7,8]$. Also, it is a solubilizing agent in the reaction. The experiments showed that the optimum concentration of $\mathrm{CTAB}$ for the postcolumn reaction is $0.5 \%$ $(\mathrm{v} / \mathrm{v})$.

\section{Effect of oxalic acid}

Oxalic acid can catalyse the chromogenic reaction of phenylfluorone with $\mathrm{Sn}^{2+}$, but it does not have any effect on the $\mathrm{HGeO}_{3}^{-}$reaction [15]. When oxalic acid was added to the postcolumn reagent, the peak height of $\mathrm{Sn}^{2+}$ in the chromatogram increased sharply whereas that of $\mathrm{HGeO}_{3}^{-}$remained the same. When the concentration of oxalic acid was $>0.016 \mathrm{~mol} / 1$, the peak height of $\mathrm{Sn}^{2+}$ became constant. It was also found that the interference in the determination of $\mathrm{Ge}$ in the presence of large amounts of $\mathrm{Sn}^{2+}$ could be easily removed by changing the concentration of oxalic acid. For the simultaneous determination of germanium and tin, $0.02 \mathrm{~mol} / \mathrm{l}$ oxalic acid in the postcolumn reagent was adopted.

Based on the above discussion, the optimum composition of the postcolumn reagent is 0.75 $\mathrm{mmol} / 1$ phenylfluorone, $0.5 \% \mathrm{CTAB}, 1.5 \mathrm{~mol} / \mathrm{l}$ $\mathrm{H}_{2} \mathrm{SO}_{4}$ and $0.02 \mathrm{~mol} / \mathrm{l}$ oxalic acid.

\subsection{Interferences}

It has been reported that some metal ions also react with phenylfluorone $[5,6,8]$. However, in this method, with elution by $\mathrm{H}_{2} \mathrm{SO}_{4}-\mathrm{Na}_{2} \mathrm{SO}_{4}$, low-valent metal ions (such as alkali and alkaline earth metals and other divalent ions, $\mathrm{Ni}^{2+}, \mathrm{Fe}^{2+}$, $\mathrm{Cu}^{2+}, \mathrm{Co}^{2+}, \mathrm{Zn}^{2+}$, etc.) cannot be retained on the IonPac CS5 separation column and are rapidly removed with the system peak; however, high-valent metal ions such as $\mathrm{Fe}^{3+}, \mathrm{Al}^{3+}$ and Mo(VI) were retained on the column for a long time. The experiments showed that there was no interference in the determination of $\mathrm{Ge}$ and $\mathrm{Sn}$ when $\mathrm{Fe}^{3+}, \mathrm{Al}^{3+}$, and $\mathrm{Mo}(\mathrm{VI})$ co-existed in the samples (when their concentration was $<1000$ times greater than that of $\mathrm{HGeO}_{3}^{-}$and $<500$ times greater than that of $\mathrm{Sn}^{2+}$ ). However, oxidants such as perchloric acid interfere in the determination of $\mathrm{Sn}^{2+}$. Compared with other methods for the determination of germanium and tin, the proposed method is simple, sensitive and highly selective and the interferences can be easily removed.

\subsection{Detection limits, linearity and reproducibility}

Table 2 gives the results for linearity, reproducibility and sensitivity. The results are satisfactory.

\subsection{Results for real samples}

We applied the method to the determination of $\mathrm{HGeO}_{3}^{-}$and $\mathrm{Sn}^{2-}$ in two kinds of samples: an alloy and an organic germanium nutritive liquid. Fig. 3 shows the chromatograms.

The preparation for the alloy involved dissolving $1.0 \mathrm{~g}$ of alloy in aqua regia, adding hydroxylamine hydrochloride in order to reduce Sn(IV) to $\mathrm{Sn}(\mathrm{II})$ and diluting to $100 \mathrm{ml}$ with deionized water.

The organic germanium nutritive liquid is a newly developed functional health product 
Table 2

Linearity, detection limits and relative standard deviations for the determination of $\mathrm{HGeO}_{3}^{-}$and $\mathrm{Sn}^{2+}$

\begin{tabular}{llll}
\hline Ion & Linearity, $r$ & R.S.D. $(\%)(n=7)$ & ${\text { Detection limit }(\mu \mathrm{g} / 1)^{\mathrm{a}}}^{\mathrm{y}}$ \\
\hline $\mathrm{HGeO}_{3}^{-}$ & $0.9998(0.5-1000 \mu \mathrm{g} / 1)$ & $1.8(0.05 \mathrm{mg} / 1)$ & 0.5 \\
$\mathrm{Sn}^{2+}$ & $0.9999(1.0-30.0 \mathrm{mg} / 1)$ & $1.1(15.0 \mathrm{mg} / 1)$ & 1.5 \\
\hline
\end{tabular}

${ }^{a}$ Signal-to-noise ratio $=3$.
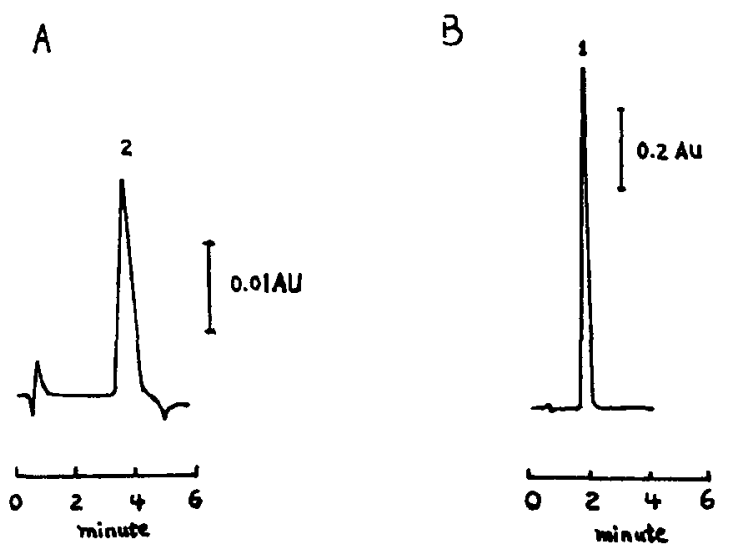

Fig. 3. Chromatograms for real sample analysis: (A) alloy; (B) organic germanium nutritive liquid. Peaks: $1=\mathrm{HGeO}_{3}^{-}$; $2=\mathrm{Sn}^{2+}$.

(Tianlong Health Nutriment, China). The sample was prepared by mixing $1 \mathrm{ml}$ of the liquid with $5 \mathrm{ml}$ of concentrated nitric acid and $1 \mathrm{ml}$ hydrogen peroxide, digesting for $2 \mathrm{~h}$ and diluting to $100 \mathrm{ml}$ with deionized water.

Spike and recovery studies were performed using the above samples and AAS was also applied for comparison purposes. The results are given in Table 3. Good recoveries for the determination of $\mathrm{Ge}$ and $\mathrm{Sn}$ were obtained (96$102 \%$ ), and the results with the proposed method were in good agreement with the AAS data.

\section{References}

[1] K. Wang, Trace Elements in Life Science, China Measurement Publishing House, Beijing, 1992, p. 511.

[2] C.L. Leong, Talanta, 18 (1971) 845.

[3] H.B. Corbin, Anal. Chem., 45 (1973) 534.

[4] Y. Chen and B. Wang, Fenxi Huaxue, 17 (1989) 498.

[5] A. Harada and T. Tarutani, Anal. Chim. Acta, 209 (1988) 333.

[6] H. Shen, Z. Wang and G. Xu, Analyst, 112 (1987) 887.

[7] Y. Shijo and T. Takeuchi, Bunseki Kagaku, 51 (1967) 161.

Table 3

Results for real samples

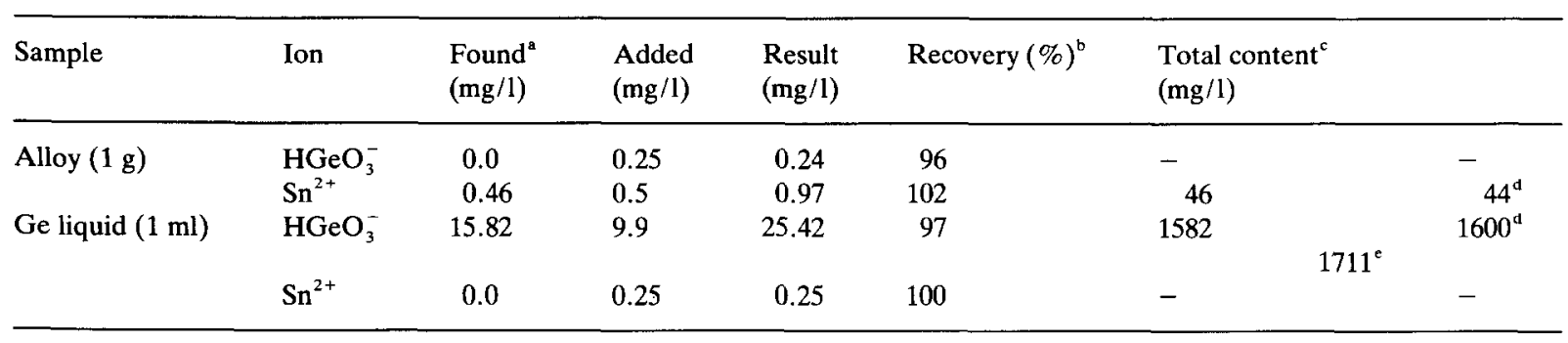

\footnotetext{
${ }^{a}$ Found in analysed samples, i.e., after dilution.

${ }^{\mathrm{b}}$ Recovery $=$ (results - found $) \times 100 /$ addition.

Total content (mg/l) of $\mathrm{HGeO}_{3}^{-}$and $\mathrm{Sn}^{2+}$ in the original (undiluted) samples ( $1 \mathrm{~g}$ of alloy or $1 \mathrm{ml}$ of $\mathrm{Ge}$ liquid).

d AAS data.

'Approximate value given by the producer.
} 
[8] D. Shang and H. Xu, Fenxi Huaxue, 3 (1975) 203.

[9] M.O. Andreae and P.N. Froelich, Jr., Anal. Chem., 53 (1981) 287.

[10] L. Halicz, Analyst, 110 (1985) 943.

[11] J.R. Castillo, At. Spectrosc., 2 (1981) 159.

[12] C.M. Joy, Anal. Chim. Acta, 142 (1982) 231.
[13] N. Li, Huaxue Xuebao, 45 (1987) 399.

[14] K. Wang, Trace Elements in Life Science, China Measurement Publishing House, Beijing, 1992, p. 540.

[15] H. Xu, D. Zhang and X. Lin, Fenxi Huaxue, 4 (1976) 218. 